\title{
Carcinoma of the Eyelid cNX TNM Finding v7
}

National Cancer Institute

\section{Source}

National Cancer Institute. Carcinoma of the Eyelid cNX TNM Finding v7. NCI Thesaurus. Code C88577.

Carcinoma of the eyelid in which the regional lymph nodes cannot be assessed. (from AJCC 7th Ed.) 